\title{
Interactive comment on "Identifying the non-exceedance probability of extreme storm surges as a component of natural-disaster management using tidal-gauge data from Typhoon Maemi in South Korea” by Sang-Guk Yum et al.
}

\section{Anonymous Referee \#4}

Received and published: 28 December 2020

Abstract : Since this is a scientific paper, it is recommended to summarize the research methodology and conclusions (major outcomes) in more detail.

Line 43 : I can't fine this paper(Hwang and Deodatis 2013) in your reference. Check please.

Line 71 : I recommend that the names of Sea of Japan and East Sea should be written as "East/Japan Sea" together.

Printer-friendly version

Discussion paper

Line 85 : In your Table $2 \& 3$, Fill the last column in line1 -> Total Sum \& Average in 
line2 3 -> Incidence(sum) \& Incidence(average)

Line 94 96 : South Korea operated 17 tidal gauge stations. -> South Korea operated 46 tidal gauge stations. And $(n=5),(n=10),(n=2) \sim$ Check please.

Line 99 : These expressions are already expressed in Figure 1 and are redundant, so please remove them.

Interactive

comment

Line 105 : Authors did not to describe about QC processes(i.e. interpolation, outliers etc) of tidal gauge data, cause tidal stations have lots of errors in raw data. Rising rate of MSL can be varied considerably according to the OC processes.

Line 106 : Highest recorded water levels -> Recorded highest water levels

Line 110 : Table 5 is presented but not cited in the text.

Line 115 : In Table 5, New Busan -> New Busan Port

Line 129 : Figure 4 and 5 -> Figure 3 and 4

Line 130 : I think it would be appropriate to delete Figure 3 because it is not important in the context described in the paper.

Line 132 : In Figure 3 \& 4, Sea level $(\mathrm{cm})$-> Mean sea level $(\mathrm{cm})$

Line 136 : Figure 4. Sea-level fluctuations around the mean, Busan -> Figure 4. Mean Sea-level fluctuations in Busan

Line 139 : "Looking at the sea-level history in Figure 3, it is clear that the data trend between 1956 and 1961 is anomalous. As this may have been due to quality-control issues with the observations from that period, it has been excluded from this study, and only data from 1962 to 2019 have been used, as shown in Figure 4." -> If you accept the recommendation, please delete this context.

Line 154 : In Table 7, New Busan -> New Busan Port

Printer-friendly version

Line 155 : As can be seen from Table 7, 
Line 185 : I can't fine this paper(Lee et al. 2008) in your reference. Check please.

Line 201 : description on Previous research results

Line 231 : Introduction on return period of Hurricane using GEV, MLE, CSPS

Line 268 : I can't fine this paper(Pickands, 1975 \& Scarrott and Macdonald 2012) in your reference. Check please.

Interactive

comment

Line 333 : Description on the surge height caused by typhoon Maemi.

Line 339 : I can't find where is the Figure 7 in the text.

Although the return period is importantly mentioned at the beginning, it is not presented in the results, and that only mentioning that further research is needed may lower the quality and justification of the paper, so additional supplementation is required. Since this is a scientific paper, the conclusion should be explained in detail.

I look forward to seeing you again with the revised thesis.

Happy New year!

Interactive comment on Nat. Hazards Earth Syst. Sci. Discuss., https://doi.org/10.5194/nhess2020-379, 2020.

Printer-friendly version

Discussion paper 